\title{
Correlation of interleukin- 2 and soluble interleukin-2 receptor with clinical activity of multiple sclerosis
}

\author{
M K Sharief, E J Thompson
}

\begin{abstract}
Concentrations of interleukin-2 (IL-2) and soluble IL-2 receptor (sIL-2R) in serum and CSF samples were measured in 63 patients with multiple sclerosis (MS) to evaluate their usefulness as markers of disease activity. CSF concentrations of IL2 and sIL-2R were significantly higher in MS relapse compared with MS patients in remission or with control subjects. These concentrations correlated with the clinical score by which disease severity was assessed, with the number of relapses per year, and with the total disease duration. Furthermore, there was evidence of intrathecal release of IL-2 and sIL-2R in clinically active MS. The results extend the notion that an activated cellular immune state parallels the evolution of the pathological process in MS and suggest that measurement of IL-2 and SIL-2R concentrations may provide an objective marker of disease activity in patients with MS
\end{abstract}

$(\mathcal{F}$ Neurol Neurosurg Psychiatry 1993;56:169-174)

There is increasing evidence that elevated concentrations of interleukin-2 (IL-2) and its soluble receptor may reflect the clinical course of multiple sclerosis (MS). ${ }^{1-5} \mathrm{~T}$ lymphocytes expressing IL-2 or IL-2 receptor have been detected in demyelinated plaques in brains obtained at necropsy of patients with active MS. ${ }^{6-8}$ Clinical studies have also reported increased concentrations of IL-2 in serum or CSF of patients with clinically active $\mathrm{MS},{ }^{9-11}$ and serum or CSF levels of soluble IL-2 receptor (sIL-2R) were shown to be significantly higher in patients with active MS compared with patients in remission. ${ }^{10} 12$ Moreover, Hartung et al $^{13}$ reported that serum concentrations of sIL-2R apparently paralleled MS disease activity although these concentrations did not correlate with the clinical score by which disease severity was assessed.

For the clinician, assessment of disease activity in MS patients is important not only from a prognostic view point, but also to monitor the efficacy of therapeutic interventions. Although MRI can visualise lesion dissemination, assessment of disease activity in MS is essentially clinical, ${ }^{14}$ relying on evidence of a relapse or increasing disability. These clinical measures, however, do not suffice because of intrinsic variability of the disease and subjective differences between clinical observers. ${ }^{15}$ We therefore elected to determine whether intrathecal levels of IL-2 and sIL-2R in MS correlate with clinical disease activity. We measured concentrations of IL-2 and sIL$2 \mathrm{R}$ in serum and CSF samples from $M S$ patients in relapse and remission, and compared the results with levels of IgG index ${ }^{16}$ which estimates the intrathecal humoral immune response.

\section{Patients and methods \\ Patients}

We obtained paired serum and CSF samples from 63 patients (39 women and 24 men; median age, $27 \cdot 2$ years; age range, $20 \cdot 5$ to 50 years) with clinically definite $\mathrm{MS} .{ }^{17}$ The median duration of the illness was $5 \cdot 2$ years (range, 1.2 to 14.5 years). All had relapsingremitting disease with high prestudy relapse rates (at least 0.7 per years) and 42 patients were in clinical relapse during CSF collection. We defined the relapse phase as within 2 weeks of worsening of existing symptoms(s) provided that the course has been stationary or has improved during the previous month. ${ }^{18}$ Remission was defined as improvement in symptoms or signs for at least one month. ${ }^{17}$ No patient involved in the study has received immunosuppressive treatment for at least 8 months from the CSF collection. The degree of disability at the time of CSF collection was assessed with the expanded disability status scale (EDSS). ${ }^{19}$ The date of onset of MS and the number of relapses per year were obtained from previous medical records

\section{Controls}

Twenty six patients with non-inflammatory nervous diseases were included in the study to serve as neurological controls. Their diagnoses included Alzheimer's disease (5 patients), motor neuron disease (6 patients), benign intracranial hypertension (4 patients), cerebrovascular diseases (7 patients), and epilepsy (4 patients). Paired samples were also obtained from 14 normal subjects who presented with non-specific headache or neurotic syndromes to serve as normal controls. Neurological examination and detailed investigations of the normal controls had excluded an organic cause of their symptoms.

\section{Sample preparation}

We excluded xanthochromic CSF samples or samples containing more than 1 erythrocyte per $\mu \mathrm{l}$ at the time of collection. All samples were filtered through a $0.45-\mu \mathrm{m}$ disposable sterile filter (Millipore) to remove contaminat- 
ing particulate materials. One thousand kallikrein inhibitor units of protease inhibitor (Aprotinin, Sigma, UK) were added to each millilitre of CSF and serum samples to prevent protein degradation. Samples were then frozen in aliquots at $-70^{\circ} \mathrm{C}$ and thawed just before use.

\section{CSF assays}

All assays were performed blind on coded sterile samples. Concentrations of IL-2 in native CSF and diluted serum were determined by a sensitive indirect enzyme-linked immunosorbent assay (ELISA). ${ }^{20}$ Inter-assay variation was a maximum of $8 \cdot 2 \%$ and intraassay variation was less than $5 \%$. The assay allowed the detection of IL-2 concentrations above 0.05 units per $\mathrm{ml}$ (U/ML). Concentrations of sIL-2R in CSF and diluted serum specimens were measured by a sandwich ELISA $^{21}$ using two different anti-IL-2R monoclonal antibodies; the first is adsorbed onto polystyrene microtitre wells and the other is peroxidase-conjugated. Inter-assay variation was less than $8.5 \%$ and intra-assay variation was a maximum of $2 \%$. The lowest amount of sIL-2R detected by this assay was $0 \cdot 1 \mathrm{U} / \mathrm{ml}$.

Albumin and IgG concentrations in CSF and serum specimens were determined by electroimmunoassay. ${ }^{22}$ Synthesis of IgG within the central nervous system (that is, intrathecal) was determined by calculating the IgG index ${ }^{16}$ according to the following formula: CSF IgG/ serum $I g G) \div$ (CSF albumin/serum albumin)

\section{Statistics}

Non-parametric Wilcoxon sum rank, Pearson correlation matrix, and chi-square tests were used, as appropriate, for statistical analysis. Confidence intervals (CI) for non-parametric data were calculated as described earlier. ${ }^{23}$

\section{Results}

Concentrations of IL-2 and sIL-2R in MS

High concentrations of IL-2 were detected in the CSF of $32(80 \%)$ patients with clinically active MS, $6(29 \%)$ MS patients in remission and $3(8 \%)$ controls ( 2 with acute stroke and 1 with post-traumatic epilepsy; fig 1). CSF IL-2 concentrations in MS relapse were significantly higher than MS patients in remission or controls, whereas serum concentrations of IL2 in MS relapse were not significantly different from those in remission (fig 1). The IgG index also failed to differentiate between MS patients in relapse and those in clinical remission $(p=$ $0 \cdot 11)$. Indeed, high IgG index values were also seen in 4 neurological controls (fig 1: 2 strokes, 1 motor neuron disease, and 1 benign intracranial hypertension).

CSF concentrations of IL-2 in MS patients in relapse correlated with CSF concentrations of sIL-2R $(r=0.719, p<0.001)$. MS patients in relapse had significantly high levels of sIL$2 \mathrm{R}$ in the CSF compared with MS patients in remission or controls (fig 2), whereas no significant difference was detected between serum levels of sIL-2R in MS relapse and remission $(p=0.07)$

Intrathecal cytokine release in clinically active MS

We standardised levels of IL-2 and sIL-2R CSF and serum of MS patients in relapse by calculating their ratios to albumin concentrations, as previously described, ${ }^{41020}$ to correct for passive transudation through blood-CSF barriers. Standardised CSF concentrations of IL-2 (95\% CI of $2 \cdot 3$ to $10 \cdot 1 \mathrm{U} / \mathrm{mg}$ of albumin) were significantly higher than corresponding serum levels $(95 \% \mathrm{CI}$ of 0.17 to $0.73 \mathrm{U} / \mathrm{mg}$ of albumin), suggesting local release of IL-2 within the intrathecal compartment. ${ }^{20} \mathrm{Sim}$ ilarly, standardised sIL-2R levels in CSF (95\% CI of 139 to $243 \mathrm{U} / \mathrm{mg}$ of albumin) were significantly higher than serum levels $(95 \%$ CI of 1.4 to $5.4 \mathrm{U} / \mathrm{mg}$ of albumin), indicating intrathecal release of sIL-2R in clinically active MS. Calculation of cytokine index values ${ }^{16}$ also detected intrathecal release of IL-2 and sIL-2R in patients with active MS (data not shown).

\section{Cytokine levels and clinical features of $M S$}

CSF concentrations of IL-2 and sIL-2R correlated with the degree of disability, as manifested by EDSS, in patients with clinically active disease (table 1). In contrast, serum levels of IL-2 or sIL-2R in these patients failed to correlate with the EDSS score. Similarly, CSF levels of IL-2 and sIL-2R in remission did not correlate with degree of disability. IgG index in patients with clinically active MS correlated with the EDSS score (table 1).

In addition to their correlation with the degree of disability, CSF concentrations of IL2 and sIL-2R in clinically active disease showed good correlation with the total number of relapses per year, and correlated inversely with total disease duration. Interestingly, serum concentrations of IL-2 and sIL-2R in clinically active MS also correlated with total disease duration $(r=0.36$ and 0.32 respectively), whereas IgG index values failed to correlate with total disease duration or the number of relapses per year (table 1 ).

\section{Discussion}

In this study, we detected higher CSF concentrations of IL-2 and sIL-2R in patients with

Table 1 Correlation of CSF levels of IL-2 and sIL-2R and values of IgG index with clinical parameters of multiple sclerosis

\begin{tabular}{lll}
\hline $\begin{array}{l}\text { Clinical } \\
\text { Parameter }\end{array}$ & $\begin{array}{l}\text { Pearson's Correlation } \\
\text { Coefficient }\end{array}$ & p value \\
\hline The EDSS score & 0.81 & $<0.001$ \\
CSF IL-2 & 0.83 & $<0.001$ \\
CSF sIL-2R & 0.63 & $<0.001$ \\
IgG index & & $<0.005$ \\
Number of relapses per year & 0.60 & $<0.001$ \\
CSF IL-2 & 0.43 & NS \\
CSF sIL-2R & 0.08 & $<0.001$ \\
IgG index & -0.78 & $<0.001$ \\
Total disease duration & -0.64 & NS \\
CSF IL-2 & -0.17 & \\
CSF sIL-2R & IgG index &
\end{tabular}

NS, not significant; EDSS, expanded disability status score. 
Figure 1 Individual concentrations of interleukin-2 (IL-2) in cerebrospinal fluid $(\mathbf{O})$ and serum $(O)$ compared with values of IgG index (D) in patients with multiple sclerosis (MS) and the controls (including 14 normal subjects). Shaded area represents values below the detection limit of the IL-2 assay. represents the cut-off value of $I g G$ index in normal subjects and bars represent confidence intervals. Horizontal interrupted line medians and $95 \%$

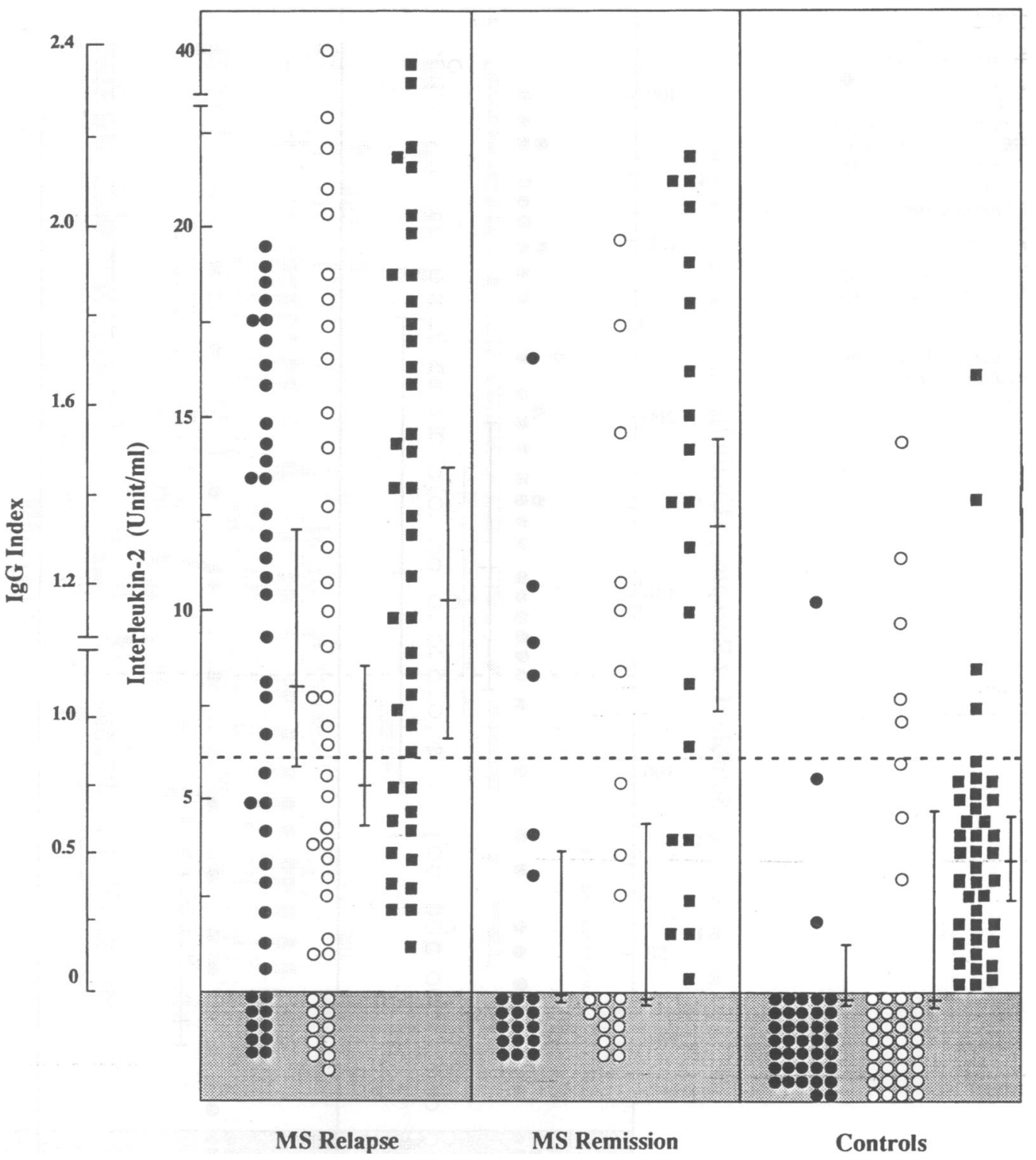

clinically active MS compared with patients in remission or neurological controls. These results agree with several independent studies, which detected high concentrations of IL-2 or sIL-2R in the CSF of patients with clinically active MS (table 2). Fesenmeier et al, ${ }^{26}$ however, were the only research group who failed to detect sIL-2R in the CSF of patients with active disease, probably because of differences in patients selection or methodological varia-

Table 2 Number of patients with active relapsing-remitting MS who had elevated IL-2 and sIL-2R in serum and CSF compared with the total number of patients studied. The table does not include studies that examined IL-2 or sIL-2R levels in serum samples alone

\begin{tabular}{|c|c|c|c|c|c|}
\hline \multirow[b]{2}{*}{ Research Group } & \multirow[b]{2}{*}{ Year } & \multicolumn{2}{|c|}{ Interleukin-2 } & \multicolumn{2}{|l|}{$s I L-2 R$} \\
\hline & & Serum & $C S F$ & Serum & $C S F$ \\
\hline $\begin{array}{l}\text { Adachi and others } \\
\text { Adachi and others } \\
\text { Gallo and others } \\
{ }^{10} \\
\text { Gallo and others } \\
\text { Gallo and others }{ }^{24} \\
\text { Kittur and others } \\
\text { Fesenmeier and others } \\
\text { Sharief and others } \\
\text { S5 }\end{array}$ & $\begin{array}{l}1989 \\
1990 \\
1988 \\
1989 \\
1991 \\
1990 \\
1991 \\
1991\end{array}$ & $\begin{array}{l}6 / 7 \\
6 / 10 \\
6 / 21 \\
20 / 36 \\
15 / 20 \\
\text { ND } \\
\text { ND } \\
34 / 36\end{array}$ & $\begin{array}{l}2 / 2 \\
4 / 6 \\
9 / 21 \\
11 / 36 \\
10 / 20 \\
\text { ND } \\
\text { ND } \\
25 / 46\end{array}$ & $\begin{array}{l}8 / 10 \\
11 / 13 \\
\mathrm{ND} \\
15 / 36 \\
20 / 20 \\
16 / 16 \\
\mathrm{ND} \\
32 / 46\end{array}$ & $\begin{array}{c}8 / 8 \\
11 / 11 \\
N D \\
0 / 36 \\
7 / 20 \\
16 / 16^{\circ} \\
0 / 11 \\
21 / 46\end{array}$ \\
\hline
\end{tabular}

ND, not done.

including patients with stable MS tions. Adachi et $a l^{410}$ and Kittur et $a l^{12}$ detected sIL-2R in the CSF of all the MS patients they investigated.

The serum and CSF concentrations of IL-2 reported here are relatively higher than those published in an earlier unrelated study. ${ }^{25}$ This difference may be due to several factors. First, the samples utilised in the earlier study did not contain a protease inhibitor and may have endured spontaneous IL-2 and sIL-2R degradation since we have consistently shown that the protease inhibitor improves cytokine detection by more than fivefold. ${ }^{20} 27$ Second, commercial ELISA kits were used to detect IL-2 in the previous study whereas a highly sensitive immunoassay ${ }^{20}$ was employed in this study. Finally, differences in patients selection may have contributed to the variation in IL-2 concentrations between the two studies.

Our study shows significant correlation of CSF IL-2 and SIL-2R concentrations with the degree of disability in MS as assessed by EDSS. Trotter et $a l^{28}$ have already reported significant correlation of serum IL-2 levels with the degree of disability in patients with progressive MS. They acknowledged, however, 
Figure 1 Individual concentrations of interleukin-2 (IL-2) in cerebrospinal fluid $(\mathbf{O})$ and serum (O) compared with values of $\operatorname{IgG}$ index (ם) in patients with multiple sclerosis (MS) and the controls (including 14 normal subjects). Shaded area represents values below the detection limit of the IL-2 assay. Horizontal interrupted line represents the cut-off value of IgG index in normal subjects and bars represent medians and $95 \%$ confidence intervals.

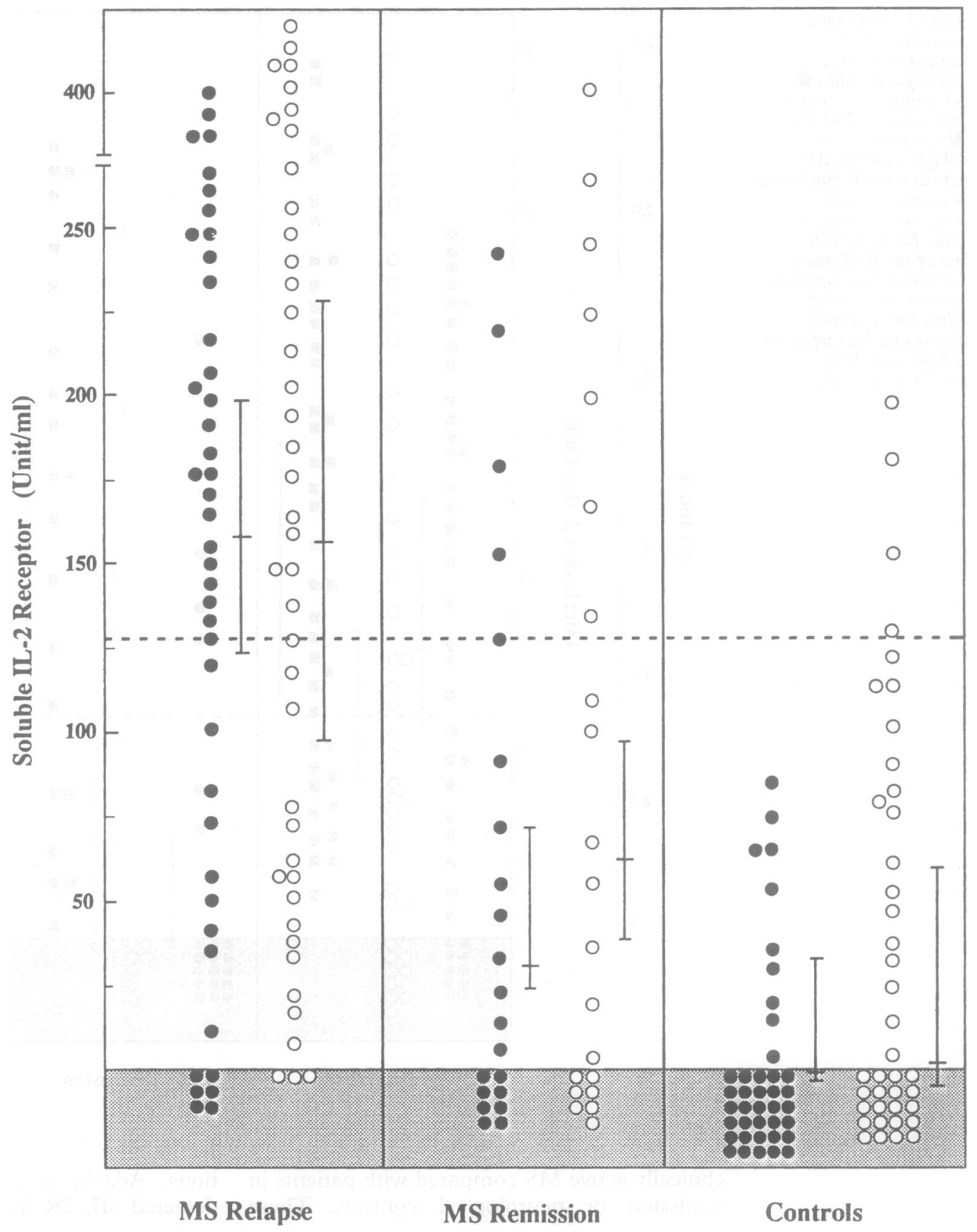

that serum levels of IL-2 may not necessarily be derived from peripheral lymphocytes, since cells staining for IL-2 may be found in plaque areas in brains of MS patients. ${ }^{7}$ We further extend their findings by reporting a significant correlation of CSF levels of IL-2 and SIL-2R with the degree of disability and relapse activity in relapsing-remitting $M S$.

The other interesting finding of this study is the higher standardised CSF levels of IL-2 and sIL-2R patients with clinically active MS compared with corresponding serum levels. This finding suggests a local release of IL-2 and its soluble receptor within the intrathecal compartment. Interleukin-2 is usually detected in both active plaques and normal appearing white matter in MS brains, ${ }^{67}$ and IL-2R-bearing lymphocytes are found in the perivascular infiltrates in MS brain lesions. ${ }^{8}$ Thus intrathecal release of IL-2 or sIL-2R may result during an active immunological process.
Indeed, local central nervous system secretion of IL-2 or sIL-2R has been demonstrated in conditions associated with an intrathecal immune response. ${ }^{29-32}$

A successful immune response involves a complex cascade of events which include the production of cytokines. IL-2, a pluripotent cytokine secreted by activated $T$ lymphocytes, ${ }^{33}$ plays an essential role in promoting replication and differentiation of $T$ lymphocytes, induction of B lymphocytes growth, and augmentation of immunoglobulin production. It exerts its pleotrophic effects via its specific high affinity receptor, which is present on activated $T$ and $B$ cells, natural killer cells, monocytes, oligodendrocytes ${ }^{34}$ and endothelial cells. ${ }^{35}$ Cell proliferation after the binding of IL-2 to its membrane receptor leads to the release of the soluble IL-2 receptor. ${ }^{33}$

The mechanism by which intrathecal release of IL-2 and sIL-2R relates to the degree of 
disability in MS patients is currently unknown. However, $T$ lymphocytes may be responsible for the progression of demyelinating plaques ${ }^{36}$ probably through the elaboration of cytokines. ${ }^{37} \mathrm{~A}$ positive correlation was also reported between the percentage of IL-2R-bearing lymphocytes and the degree of demyelination induced in vitro by supernatant from MS T lymphocytes. ${ }^{37}$ Such reports indicate that IL-2 or sIL-2R are pathophysiologically important in the demyelination process. Moreover, we have reported in a different series of patients and samples, ${ }^{38}$ which did not overlap with the present study, that intrathecal release of IL-2 and SIL-2R is related to blood-brain barrier damage in active $\mathrm{MS}$ - a finding that may partly explain the correlation between IL-2 and disease severity. We are unable at present to comment whether a cross-sectional measurement of increased CSF levels of IL-2 or sIL-2R can reflect ongoing disease activity. Longitudinal studies involving serial testing are therefore indicated.

The finding of higher intrathecal concentrations of IL-2 or sIL-2R in patients with MS relapse compared with patients in remission reported here agrees with recent reports. ${ }^{9-11}$ However, it should be pointed out that MRI reveals an apparent change in the central nervous system in some MS patients without evidence of clinical change ${ }^{39}$ whereas, in other patients, extensive dissemination of plaques may be accompanied by no or only slight disability. The correlation of intrathecal release of IL-2 or sIL-2R with MRI-detected lesion burden is currently unknown but will be the subject of future studies.

The inverse correlation between intrathecal release of IL-2 or sIL-2R and total MS disease duration reported here confirms and extends our earlier observation that local cytokine release in MS correlates with intrathecal synthesis of $\operatorname{IgM}$ and $\operatorname{IgD} .^{25}$ The process of immunoglobulin class switching from IgM to IgD or to other isotypes is important for the success of the humoral immune response. We have already demonstrated that intrathecal synthesis of IgM commonly indicates a recent immune response within the central nervous system $^{4041}$ and that it is a reliable indicator of MS disease activity. ${ }^{42}$ Therefore higher intrathecal concentrations of IL-2 and SIL-2R in MS patients with shorter disease duration may indicate relatively recent immune process.

Our results suggest the presence of activated $T$ lymphocytes within the central nervous system in MS and extend the notion that an activated cellular immune response parallels the evolution of the demyelinating process in this disease. CSF levels of IL-2 and sIL-2R appear to be a reasonable pathological marker of disease activity in MS. A laboratory test that reflects disease activity is very useful not only for its diagnostic and prognostic significance but also to monitor response to treatment.

1 CalderVL, Bellamy AS, Owen S, et al. Effects of cyclosporin A on expression of IL-2 and IL-2 receptors in normal and multiple sclerosis patients. Clin Exp Immunol 1987;70: 570-7.
2 Selmaj K, Plater-Zyberk C, Rockett KA, et al. Multiple sclerosis: increased expression of interleukin-2 receptors on lymphocytes. Neurology 1986;36:1392-5.

3 Greenberg SJ, Marcon L, Hurwitz BJ, Waldmann TA, Nelson DL. Elevated levels of soluble interleukin-2 receptors in multiple sclerosis. $N$ Eng $f$ Med 1988; receptors in

4 Adachi K, Kumamoto T, Araki S. Interleukin-2 receptor levels indicating relapse in multiple sclerosis. Lance 1989;i:559-60.

5 Trotter JL, van der Veen RC, Clifford DB. Serial studies of serum interleukin-2 in chronic progressive MS patients: occurrence of 'bursts' and effect of cyclosporine. f Neuroimmunol 1990;28:9-14.

6 Cuzner ML, Hayes GM, Newcombe J, Woodroofe MN. The nature of inflammatory components during demyelination in multiple sclerosis. $f$ Neuroimmunol 1988;20. 203-9.

7 Hofman FM, von Hanwehr RI, Dinarello CA, et al. Immunoregulatory molecules and Il-2 receptors identified in multiple sclerosis brain. I Immunol 1986; 136:3239-45.

8 Bellamy AS, Calder VL, Feldmann M, Davidson AN. The distribution of IL-2 receptor bearing lymphocytes in MS evidence for a key role of activated lymphocytes. Clin Exp Immunol 1985;61:248-56.

9 Gallo P, Piccinno M, Pagni S, Tavolato B. Interleukin-2 levels in serum and cerebrospinal fluid of multiple sclerosis patients. Ann Neurol 1988;24:795-7.

10 Adachi K, Kumamoto T, Araki S. Elevated soluble interleukin-2 receptor levels in patients with active multiple sclerosis. Ann Neurol 1990;28:687-91.

11 Gallo P, Piccinno M, Pagni S, et al. Immune activation in multiple sclerosis: study of IL-2, sIL-2R, $;-$-IFN levels in serum and cerebrospinal fluid. $f$ Neurol Sci 1989; 92:9-15.

12 Kittur SD, Kittur DS, Soncrant TT, et al. Soluble interleukin-2 receptors in cerebrospinal fluid from individuals
with various neurological disorders. Ann Neurol 1990; with various

13 Hartung HP, Hughes RAC, Taylor WA, Heininger $\mathrm{K}$, Reiners K, Toyka KV. T cell activation in Guillain-Barre syndrome and in MS: elevated serum levels of soluble IL2 receptors. Neurology 1990;40:215-8.

14 Poser S, Raun NE, Poser W. Age at onset, initial symptomatology and the course of MS. Acta Neurol Scand 1982;66:355-62.

15 Noseworthy JH, Vandervoort MK, Wong CJ, et al. Interrater variability with the expanded disability status scale (EDSS) and functional systems (FS) in a multiple sclerosis clinical trial. Neurology 1990;40:971-5.

16 Tibbling G, Link H, Ohman S. Principles of albumin and IgG analyses in neurological diseases. Establishment of IgG analyses in neurological diseases. Establishment of
reference values. Scand $f$ Clin Lab Inves 1977;37: reference $285-390$.

17 Poser CM, Paty DW, Scheinberg L, et al. New diagnostic criteria for multiple sclerosis: Guidelines for research protocols. Ann Neurol 1983;13:227-31.

18 Rose AS, Kusma JW, Kurtzke JF, et al. Cooperative study in the evaluation of therapy in multiple sclerosis: ACTH vs placebo: final report. Neurology 1970;20:1-59.

19 Kurtzke JF. Rating neurologic impairment in multiple sclerosis: and expanded disability status scale (EDSS) Neurology 1983;33:1444-52.

20 Sharief MK, Hentges R, Thompson EJ. Determination of interleukin- 2 in cerebrospinal fluid by a sensitive enzymelinked immunosorbent assay. F Immunol Meth 1992; 147:51-6.

21 Zucchelli GC, Clerico A, De Maria R, et al. Increased circulating concentrations of IL-2 receptor during rejeccirculating concentrations of IL-2 receptor during rejection episodes in heart- or
Clin Chem 1990;36:2106-9.

22 Ganrot K, Laurell CB. Measurement of IgG and albumin content of CSF, and its interpretation. Clin Chem 1974; 20:571-3.

23 Campbell MJ, Gardner MJ. Calculating confidence intervals for some non-parametric analyses. $B M \mathcal{F} 1988$ 296:1454-6.

24 Gallo P, Piccinno MG, Tavolato B, Siden A. A longitudinal study on IL-2, sIL-2R, IL-4 and IFN- $\because$ in multiple sclerosis CSF and serum. I Neurol Sci 1991;101: 227-32.

25 Sharief MK, Hentges R, Thompson EJ. The relationship of IL-2 and soluble IL-2 receptors to intrathecal immunoglobulins synthesis in patients with multiple sclerosis. $f$ globulins synthesis in patients
Neuroimmunol 1991;32:43-51.

26 Fesenmeier JT, Whitaker JN, Herman PK, Walker DP. Cerebrospinal fluid levels of myelin basic protein-like material and soluble interleukin-2 receptor in multiple material and soluble interleukin-2 receptor
sclerosis. $\mathcal{f}$ Neuroimmonol 1991;34:77-80.

27 Sharief MK, Hentges R. Association between tumor necrosis factor-a and disease progression in patients with multiple sclerosis. N Eng $\mathcal{f}$ Med 1991;325:467-72.

28 Trotter JL, Clifford DB, McInnis JE, et al. Correlation of immunological studies and disease progression in chronic progressive multiple sclerosis. An Neurol 1989;25:172-8.

29 Green WC, Leonard WJ, Depper JM, Nelson DL, Waldmann TA. The human interleukin-2 receptor: normal and abnormal expression in $T$ cells and in leukaemias induced by the human T-lymphotropic retroviruses. Ann Intern Med 1986;105:560-72.

30 Boutin B, Matsuguchi L, Lebon P, et al. Soluble IL-2 receptors in acute and subacute encephalitis. Ann Neuro 1987;22: 658-61.

31 Lang JM, Coumaros G, Levy S, et al. Elevated serum levels 
of soluble interleukin 2 receptors in HIV infection: correlation studies with markers of cell activation. Immunol Lett 1988;19:99-102.

32 Griffin DE, Ward BJ, Jaurique E, Johnson RT, Vaisberg A Immune acti

33 Smith $\mathrm{KA}$ Interleukin-2: inception, impact, and implications. Science 1988;240:1169-76.

34 Saneto RP Altman A, Knobler RK, Johnson HM, De Vellis $\mathrm{J}$. Interleukin-2 mediates the inhibition of toligodenJ. Interleukin-2 mediates the inhibition of xoligodendrocyte progenitor cell proliferati

35 Hicks C, Cooley MA, Penny R. Investigation of interleukin 2 receptors on human endothelial cells. Growth Factors 1991;5:201-8.

36 Traugott U, Reinherz EL, Riane CS. Multiple sclerosis: distribution of T-cells, T-cell subsets and Ia-positive macrophages in lesions of different ages. $\mathcal{F}$ Neuroimmintol $1983 ; 4: 201-21$.

37 Selmaj K, Bradbury K, Chapman J. Multiple sclerosis: effects of activated T-lymphocyte-derived products on organ cultures of nervous tissue. $\mathcal{f}$ Neuroimmunol 1988 ; 18:255-68

38 Sharief MK, Hentges R, Ciardi M, Thompson EJ. In vivo relationship of interleukin-2 and soluble IL-2 receptor to blood-brain barrier impairment in patients with active multiple sclerosis $\mathcal{f}$ Neurol 1993;240:46-50.

39 Paty DW. Magnetic resonance imaging in demyelination. In: Kim SU, ed. Myelination and demyelination. Implications for EJ. Immunoglobulin $M$ in the dicator of recent immunologica stimulation. I Neurol Neurosurg Psychiatry 1989;52: 949-53.

41. Sharief MK, Thompson EJ. The predictive value of intrathecal immunoglobulin synthesis and MRI in acute isolated syndromes for subsequent development of MS Ann Neurol 1991;29:147-51.

42: Sharief MK, Thompson EJ. Intrathecal immunoglobulin $M$ synthesis in multiple sclerosis. Relationship with clinical and cerebrospinal fluid parameters. Brain 1991;114: 181-95. 